\title{
Simultaneous wireless and high-resolution detection of nucleus accumbens shell ethanol concentrations and free motion of rats upon voluntary ethanol intake
}

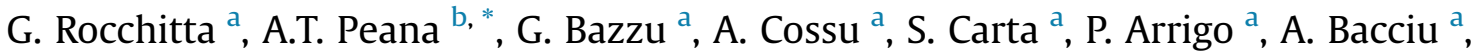 \\ R. Migheli ${ }^{a}$, D. Farina ${ }^{a}$, M. Zinellu ${ }^{\text {a }}$, E. Acquas ${ }^{\text {c}}$, P.A. Serra ${ }^{\text {a, }}{ }^{* *}$ \\ ${ }^{a}$ Department of Medical, Surgical and Experimental Sciences, Section of Pharmacology, University of Sassari, V. le S. Pietro 43/B, 07100, Sassari, Italy \\ ${ }^{\mathrm{b}}$ Department of Chemistry and Pharmacy, University of Sassari, via Muroni 23, 07100 Sassari, Italy \\ ${ }^{c}$ Department of Life and Environmental Sciences and Centre of Excellence on Neurobiology of Addiction, University of Cagliari, University Campus, I-09042, \\ Monserrato, Cagliari, Italy
}

\section{A R T I C L E I N F O}

\section{Article history:}

Received 27 February 2019

Received in revised form

28 March 2019

Accepted 10 April 2019

\section{Keywords:}

Alcohol oxidase

Ethanol

Biosensor

Microvibration sensor

Voluntary ethanol intake

Sprague Dawley rats

Telemetry

\begin{abstract}
A B S T R A C T
Highly sensitive detection of ethanol concentrations in discrete brain regions of rats voluntarily accessing ethanol, with high temporal resolution, would represent a source of greatly desirable data in studies devoted to understanding the kinetics of the neurobiological basis of ethanol's ability to impact behavior. In the present study, we present a series of experiments aiming to validate and apply an original hightech implantable device, consisting of the coupling, for the first time, of an amperometric biosensor for brain ethanol detection, with a sensor for detecting the microvibrations of the animal. This device allows the real-time comparison between the ethanol intake, its cerebral concentrations, and their effect on the motion when the animal is in the condition of voluntary drinking. To this end, we assessed in vitro the efficiency of three different biosensor designs loading diverse alcohol oxidase enzymes (AOx) obtained from three different AOx-donor strains: Hansenula polymorpha, Candida boidinii, and Pichia pastoris. In vitro data disclosed that the devices loading $H$. polymorpha and $C$. boidinii were similarly efficient (respectively, linear region slope [LRS]: $1.98 \pm 0.07$ and $1.38 \pm 0.04 \mathrm{nA} / \mathrm{mM}$ ) but significantly less than the P. pastoris-loaded one (LRS: $7.57 \pm 0.12 \mathrm{nA} / \mathrm{mM}$ ). The in vivo results indicate that this last biosensor design detected the rise of ethanol in the nucleus accumbens shell (AcbSh) after 15 minutes of voluntary 10\% ethanol solution intake. At the same time, the microvibration sensor detected a significant increase in the rat's motion signal. Notably, both the biosensor and microvibration sensor described similar and parallel time-dependent U-shaped curves, thus providing a highly sensitive and time-locked high-resolution detection of the neurochemical and behavioral kinetics upon voluntary ethanol intake. The results overall indicate that such a dual telemetry unit represents a powerful device which, implanted in different brain areas, may boost further investigations on the neurobiological mechanisms that underlie ethanolinduced motor activity and reward.
\end{abstract}

() 2019 Elsevier Inc. All rights reserved.

\section{Introduction}

The progression of ethanol consumption into alcohol use disorders (AUD) is a serious health issue, and a better understanding of the underlying neurobiological mechanisms may lead to the development of efficacious treatments for this disorder (Gilpin \&

* Corresponding author. Tel.: +39 079 228738; fax: +39079 228715.

** Corresponding author. Tel. +39 079 228558; fax: +39079 228525.

E-mail addresses: apeana@uniss.it (A.T. Peana), paserra@uniss.it (P.A. Serra).
Koob, 2008). Ethanol acts, paradoxically, as both a sedative and a stimulant drug across both dose and time (Addicott, MarshRichard, Mathias, \& Dougherty, 2007; Correa et al., 2009; Fernández et al., 2016; Rodd et al., 2004; Sánchez-Catalán, Hipólito, Zornoza, Polache, \& Granero, 2009; Tambour, Didone, Tirelli, \& Quertemont, 2006). The stimulatory effects in humans are thought to be more rewarding than the sedative ones, and thus ethanol may play a more prominent role in determining addiction (Holdstock \& de Wit, 1998). 
On the preclinical side, the behavioral effects observed after ethanol ingestion have been widely characterized, but the time at which ethanol reaches specific areas of the brain, its concentrations, and the kinetics by which ethanol metabolism translates into changes in behavior, are still unclear. Indeed, efforts in this regard have been hampered mostly by the difficulty of directly determining in-in vivo ethanol and metabolites levels in the central nervous system and thus, the present knowledge is based on indirect evidence.

Numerous techniques in animal models have been aimed at detecting ethanol concentration either in the whole brain or in discrete regions (Rocchitta \& Serra, 2013). Among them, although mostly used to assess changes in neurotransmitters concentrations, in vivo brain microdialysis has been the most exploited. This technique allows collecting information about neurochemicals in the extracellular space by means of the implantation of a semipermeable probe ( $300-\mu \mathrm{m}$ outer diameter). Indeed, after over 30 years, brain microdialysis still represents a very powerful approach whose pros and cons have been elegantly and thoroughly discussed in seminal reviews (Di Chiara, Tanda, \& Carboni, 1996; Kennedy, 2013; Rocchitta \& Serra, 2013). In particular, brain microdialysis has proven to be slightly invasive and characterized by a relatively low temporal resolution, and characterized by requiring an association with an analytical instrumentation for the analysis of collected samples (Rocchitta \& Serra, 2013). In an attempt to circumvent these limitations, in recent years different electrochemical devices have been developed, such as the amperometric biosensors (Rocchitta \& Serra, 2013), that allow real-time monitoring of molecules present in the extracellular fluids of the brain with greater temporal resolution. Interestingly, several papers have been published to date reporting the development of biosensors of different design, which are able to monitor the modifications of ethanol concentrations in the rat brain (Rocchitta et al., 2012; Secchi et al., 2013). These biosensors exploit the capability of their biological component, the alcohol oxidase enzyme (AOx), to specifically recognize and transform a substrate, ethanol, into a byproduct, hydrogen peroxide $\left(\mathrm{H}_{2} \mathrm{O}_{2}\right)$, that is easily oxidizable on a transducer surface when an anodic potential is applied (Rocchitta et al., 2012; Rocchitta \& Serra, 2013; Secchi et al., 2013) (Fig. 1).

In particular, $\mathrm{AOx}$ is capable of promoting the oxidation of aliphatic short-chain alcohols, including ethanol, into their respective aldehydes (reaction 1) according to the following scheme:

$$
\mathrm{CH}_{3} \mathrm{CH}_{2} \mathrm{OH}+\mathrm{AOx} / \mathrm{FAD} \rightarrow \mathrm{CH}_{3} \mathrm{CHO}+\mathrm{AOx} / \mathrm{FADH}_{2}
$$

AOx, in turn, is restored into its oxidized state by the action of the reducing species $\mathrm{FADH}_{2}$ and $\mathrm{O}_{2}$ (reaction 2)

$\mathrm{AOx} / \mathrm{FADH}_{2}+\mathrm{O}_{2} \rightarrow \mathrm{AOx} / \mathrm{FAD}+\mathrm{H}_{2} \mathrm{O}_{2}$

and the generated $\mathrm{H}_{2} \mathrm{O}_{2}$ is easily oxidizable by applying an anodic potential of $+700 \mathrm{mV}$ vs. $\mathrm{Ag} / \mathrm{AgCl}(\mathrm{NaCl} 3 \mathrm{M})$, as follows (reaction 3):

$\mathrm{H}_{2} \mathrm{O}_{2} \rightarrow \mathrm{O}_{2}+2 \mathrm{H}^{+}+2 \mathrm{e}^{-}$

Due to their high temporal, chemical, and anatomical resolution, biosensors could provide an innovative technology for simultaneously studying ethanol pharmacokinetic and neurochemical and behavioral downstream consequences, in discrete brain regions. Biosensors have gained much consideration recently for their ability to real-time monitor in real time biological signals in vivo and, indeed, several micro- and nano-structured devices have been successfully used in in vivo studies (Rocchitta et al., 2012; Rocchitta,
Secchi, et al., 2013; Secchi et al., 2013). Previously, our research group published a paper (Rocchitta, Secchi, et al., 2013) in which glucose and lactate amperometric biosensors were coupled, in a biotelemetric system, to a sensor for the detection of micromovements in animal models. In this novel approach, in order to improve the device's applicability, we decided to associate the biosensor for the ethanol measurements in the brain to the microvibration sensor, with the intent of correlating in real time the amount of ethanol present in the brain with the movements of rats voluntarily drinking a $10 \% \mathrm{v} / \mathrm{v}$ ethanol solution, with an original combination of chemical and physical sensors. To this end, we initially characterized in vitro a number of kinetic and analytical parameters including $\mathrm{V}_{\mathrm{MAX}}, \mathrm{K}_{\mathrm{M}}$, and linear region slope (LRS) of three different AOx-loaded biosensors (Hansenula polymorpha, Candida boidinii, and $P$. pastoris). The best performing biosensor was then coupled with a microvibration sensor in a biotelemetric device, which had been stereotaxically implanted in the shell of the nucleus accumbens (AcbSh). This brain region was chosen because it is significantly involved in ethanol-reinforcing properties following both involuntary and voluntary ethanol administration (Bassareo, Cucca, Frau, \& Di Chiara, 2017; Gonzales, Job, \& Doyon, 2004; Griffin, Middaugh, \& Becker, 2007; Melendez, Hicks, Cagle, \& Kalivas, 2005; Middaugh, Szumlinski, Van Patten, Marlowe, \& Kalivas, 2003; Moghaddam \& Bolinao, 1994; Nie, Madamba, \& Siggins, 1994; Weiss, Lorang, Bloom, \& Koob, 1993).

\section{Materials and methods}

This study was carried out in accordance with the Italian legislation (art. 31 D. Legs. 26, 2014), which allows experimentation on laboratory animals only after submission and approval of a research project by the welfare and health organization on animal experimentation at the authors' institution of affiliation (University of Sassari, Sassari, Italy) and to the Ministry of Health (Rome, Italy), and in accordance with the European Council directives (n. 2007) $526 / C E$ ) on the matter. All possible efforts were made to minimize animal pain and discomfort and to reduce the number of experimental subjects.

\section{Animals}

Male Sprague Dawley rats (Envigo; Udine, Italy), weighing 100-124 g at the beginning of the experiment, were housed in pairs in plexiglass cages with tap water (provided by two bottles/ cage) and food (Envigo; Udine, Italy) available ad libitum. The colony room was maintained under controlled environmental conditions (temperature: $22 \pm 2{ }^{\circ} \mathrm{C}$; humidity: 60-65\%) on a 12/12-hour light/dark cycle (lights on at 8:00 AM). To minimize stress, subjects were habituated to the experimental procedures (handling) for at least three days before the beginning of the experiment. Experiments were conducted during the light phase of the light/dark cycle. Animals were divided in two experimental groups: "controls" (just water) and "ethanol" (free choice between water and ethanol solution).

\section{Drugs and chemicals}

All compounds were obtained from Sigma-Aldrich (Milan, Italy). Phosphate-buffered saline (PBS) $100 \mathrm{mM}$ was prepared by mixing $\mathrm{NaCl}$ (8.9 g), $\mathrm{NaOH}$ (1.76 g), and $\mathrm{NaH}_{2} \mathrm{PO}_{4}(6.89 \mathrm{~g})$ in $1 \mathrm{~L}$ of distilled water, which was then buffered at $\mathrm{pH}$ 7.4. The stock solution of alcohol oxidases (AOx) (EC 1.1.3.13) from different yeast strains was prepared as $200 \mathrm{U} / \mathrm{mL}$ in PBS. Ethanol solutions for calibrations ( $10 \mathrm{mM}$ and $1 \mathrm{M}$ ) were prepared from absolute ethanol by dilution in distilled water. Ascorbic acid (AA) stock solution 


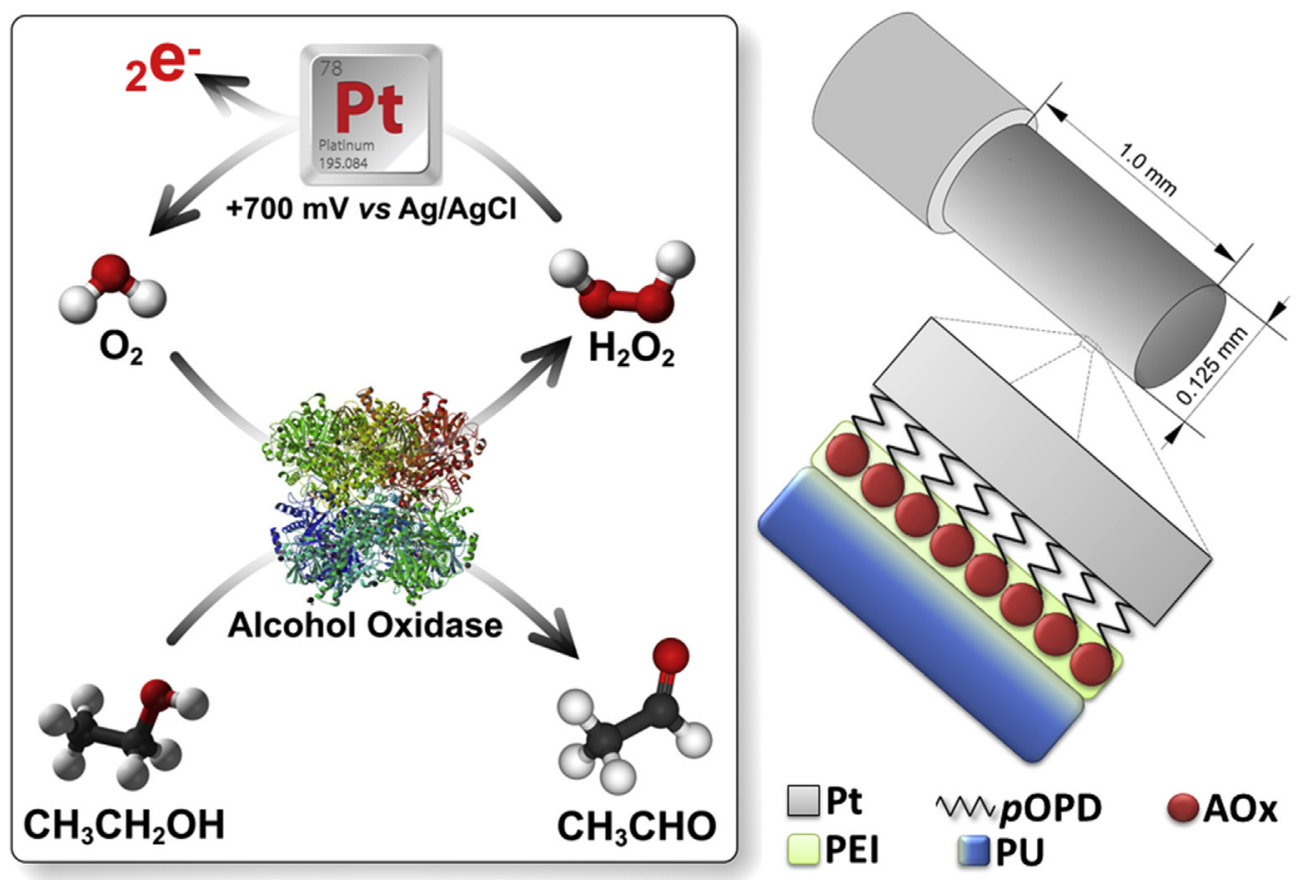

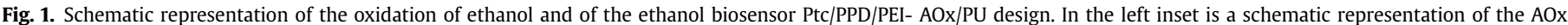

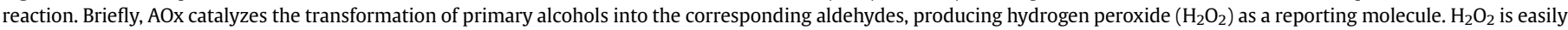

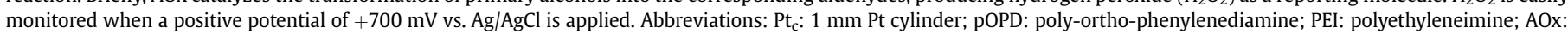
alcohol oxidase; PU: polyurethane.

(100 mM) was prepared by solubilizing L-ascorbic acid powder in $0.01 \mathrm{M} \mathrm{HCl}$.

Polyethyleneimine (PEI) solution $1 \% \mathrm{w} / \mathrm{v}$ was prepared by dilution of the stock solution $(50 \% \mathrm{w} / \mathrm{v})$ with distilled water. Glycerol solution (1\%) was obtained by diluting the stock solution (87\%) with distilled water. The polymerizing solution of orthophenylenediamine monomer (o-PD, $300 \mathrm{mM}$ ) was obtained by dissolving the powder in $20 \mathrm{~mL}$ of deoxygenated PBS.

Polyurethane (PU) solution was obtained at the concentration of $1 \% \mathrm{w} / \mathrm{v}$ by dissolving PU beads in tetrahydrofuran (THF). Teflon ${ }^{\circledR}$ coated platinum $(90 \% \mathrm{Pt}, 10 \% \mathrm{Ir} ; \varnothing=125 \mu \mathrm{m})$ and silver wires $(\varnothing=250 \mu \mathrm{m})$ were purchased from Advent Research Materials (Eynsham, England).

Ethanol solutions ( $10 \% \mathrm{v} / \mathrm{v}$ ) were obtained by dilution of ethanol (95\%; Silvio Carta, Italy) with tap water. In particular, to obtain $1 \mathrm{~g} /$ $\mathrm{kg}$ of ethanol, each rat (263 $\mathrm{g}$ of average body weight) had to drink $3.33 \mathrm{~mL}$ of ethanol solution. All ethanol solutions were freshly prepared before experiments.

\section{Ethanol biosensor fabrication and characterization}

As previously described (Rocchitta et al., 2012), biosensors were manufactured by cutting a portion of $30 \mathrm{~mm}$ of a platinum/iridium wire by uncovering $1 \mathrm{~mm}$ of bare metal and by removing the Teflon ${ }^{\circledR}$ insulation. The wire was inserted into an $8-\mathrm{mm}$ length of a $10-\mu \mathrm{L}$ micropipette tip, so that the end of the exposed metal resulted $9.6 \mathrm{~mm}$ from the micropipette tip edge, and was then fixed with epoxy glue. This arrangement made it possible to obtain a 1$\mathrm{mm}$ protrusion of the future biosensor from the end of the guide cannula, once implanted (see paragraph "Stereotaxic surgery and in vivo experimental procedures").

At day 0 , the electrodeposition of the polymer from o-PD was carried out by immersing the exposed portion of the metal to the monomer solution (o-PD $300 \mathrm{mM}$ ) and by applying a constant anodic potential of $+700 \mathrm{mV}$ vs. $\mathrm{Ag} / \mathrm{AgCl}$ for 15 minutes. The polymer is necessary in order to block the currents derived from AA, which represent the greatest interference in the extracellular space (Kirwan et al., 2007; Rocchitta et al., 2012; Rocchitta, Secchi, et al., 2013; Rocchitta \& Serra, 2013). Then, different AOx enzymes (H. polymorpha, C. boidinii, and P. pastoris, one for each biosensor group - four biosensors for each group) were loaded with the enzyme stabilizers, PEI $1 \%$ and glycerol (1\%), by means of 10 dip evaporations, and then letting them dry for 5 minutes each. Finally, in order to entrap all the layers, the biosensors were dipped in a $1 \%$ polyurethane (PU) solution one time and then were allowed to dry at room temperature for 30 minutes. Following the manufacture, biosensors were immersed in $20 \mathrm{~mL}$ of fresh PBS, and a constant potential of $+700 \mathrm{mV}$ vs. $\mathrm{Ag} / \mathrm{AgCl}$ was applied in order to let currents stabilize overnight. Biosensors were calibrated at day 1 by means of a full calibration performed by adding known volumes of ethanol standard solutions ( $10 \mathrm{mM}$ and $1 \mathrm{M}$ ) in $20 \mathrm{~mL}$ of fresh PBS at room temperature $\left(25 \pm 2{ }^{\circ} \mathrm{C}\right)$, ranging from 0 up to $170 \mathrm{mM}$ of ethanol concentration. Current data were fitted with the Michaelis-Menten enzyme kinetics equation for a two-substrate system (O'Neill, Rocchitta, McMahon, Serra, \& Lowry, 2008; Puggioni et al., 2019; Rocchitta et al., 2018) (Fig. 2).

The final design for the biosensors was $\mathrm{Pt}_{\mathrm{c}} / \mathrm{PPD} /[\{\mathrm{PEI}(1 \%)+$ Glyc (1\%)\}/AOx $]_{10} / \mathrm{PU}(1 \%)$.

In parallel, in order to evaluate and eliminate any possible contribution from non-biosensor signals during in vivo experiments, the enzyme-free sentinel biosensors were built by using the same protocol for manufacturing and characterizing the biosensors. The final design for the sentinel biosensors was $\mathrm{Pt}_{\mathrm{c}} / \mathrm{PPD} /[\{\mathrm{PEI}$ (1\%) + Glyc (1\%) $]_{10} / \mathrm{PU}(1 \%)$.

At day 1, AA shielding of biosensors and sentinel sensors was assessed (data not shown) in fresh PBS at room temperature. A fixed potential of $+700 \mathrm{mV}$ vs. $\mathrm{Ag} / \mathrm{AgCl}$ was applied and, after having reached a stable baseline, biosensors and sentinel sensors 


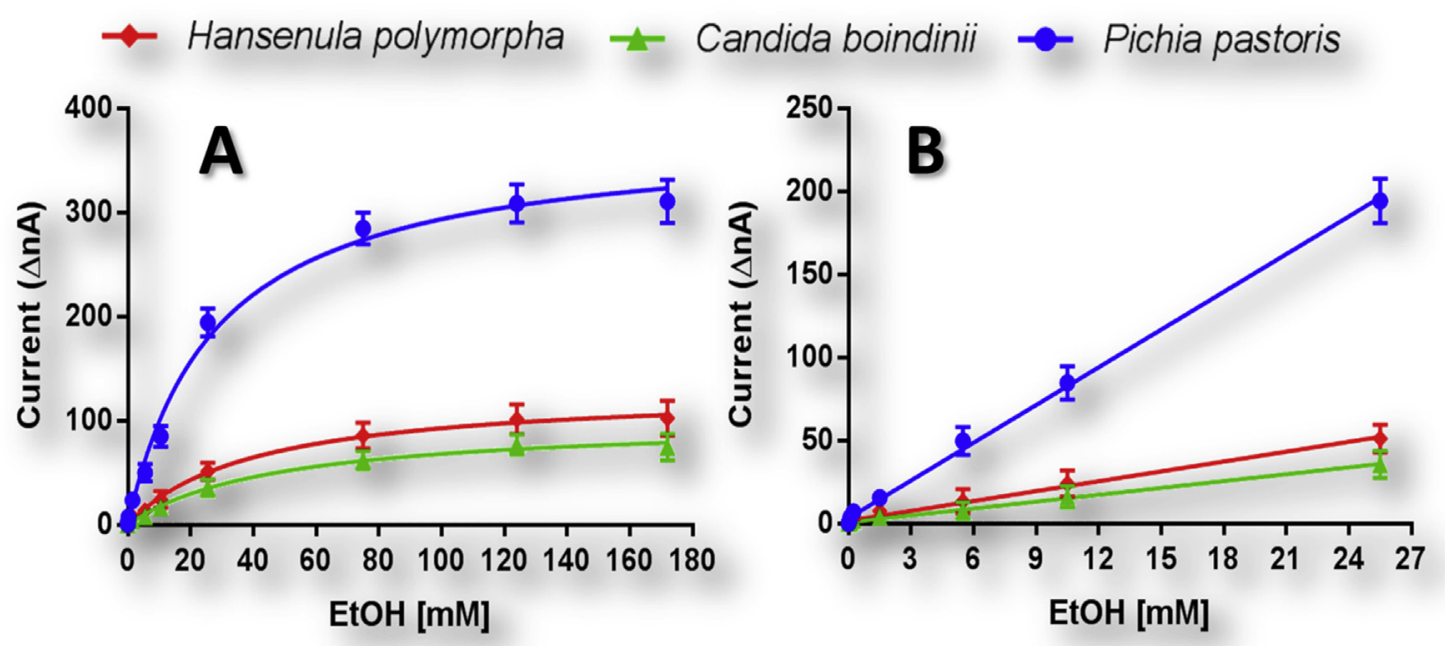

\begin{tabular}{|c|c|c|c|c|c|c|c|c|}
\hline AOx source & $\begin{array}{l}\mathrm{V}_{\mathrm{MAX}} \pm \\
\text { SEM } \\
\text { (nA) }\end{array}$ & $\begin{array}{l}\mathrm{K}_{\mathrm{M}} \pm \\
\text { SEM } \\
(\mathrm{mM})\end{array}$ & $\begin{array}{c}\text { LRS } \pm \\
\text { SEM } \\
\left(\mathrm{nA} \mathrm{mM}^{-1}\right)\end{array}$ & $\begin{array}{c}\text { LOD } \pm \\
\text { SEM } \\
\text { (mM) }\end{array}$ & $\begin{array}{l}\text { LOQ } \pm \\
\text { SEM } \\
\text { (mM) }\end{array}$ & $\begin{array}{l}\text { AA I } \text { lim } \pm \\
\text { SEM } \\
\text { (nA) }\end{array}$ & $\begin{array}{l}\text { AA } \Delta \mathrm{I} \pm \\
\text { SEM } \\
\text { (nA) }\end{array}$ & $\begin{array}{c}\text { Response } \\
\text { time } \pm S D \\
\text { (S) }\end{array}$ \\
\hline $\begin{array}{c}\text { Hansenula } \\
\text { polymorpha }\end{array}$ & $\begin{array}{l}130.3 \pm \\
12.4\end{array}$ & $\begin{array}{l}40.7 \pm \\
11.6\end{array}$ & $\begin{array}{c}2.0 \pm \\
0.1\end{array}$ & $\begin{array}{l}0.1 \pm \\
0.04\end{array}$ & $\begin{array}{c}0.3 \pm \\
0.1\end{array}$ & $\begin{array}{l}1.6 \pm \\
0.4\end{array}$ & $\begin{array}{c}0.5 \pm \\
0.1\end{array}$ & $\begin{array}{l}1.5 \pm \\
0.8\end{array}$ \\
\hline $\begin{array}{l}\text { Candida } \\
\text { boindinii }\end{array}$ & $\begin{array}{c}100.5 \pm \\
10.7\end{array}$ & $\begin{array}{l}47.7 \pm \\
11.4\end{array}$ & $\begin{array}{l}1.4 \pm \\
0.04\end{array}$ & $\begin{array}{l}0.2 \pm \\
0.6\end{array}$ & $\begin{array}{c}0.5 \pm \\
0.2\end{array}$ & $\begin{array}{l}1.4 \pm \\
0.5\end{array}$ & $\begin{array}{c}0.4 \pm \\
0.1\end{array}$ & $\begin{array}{l}1.9 \pm \\
0.7\end{array}$ \\
\hline $\begin{array}{l}\text { Pichia } \\
\text { pastoris }\end{array}$ & $\begin{array}{c}375.6 \pm^{*} \\
13.2\end{array}$ & $\begin{array}{c}28.0 \pm \\
3.3\end{array}$ & $\begin{array}{c}7.6 \pm \\
0.1\end{array}$ & $\begin{array}{c}0.05 \pm^{*} \\
0.03\end{array}$ & $\begin{array}{l}0.2 \pm \\
0.07\end{array}$ & $\begin{array}{c}1.4 \pm \\
0.4\end{array}$ & $\begin{array}{l}0.3 \pm \\
0.2\end{array}$ & $\begin{array}{c}1.1 \pm \\
0.4\end{array}$ \\
\hline $\begin{array}{l}\text { Sentinel } \\
\text { sensor }\end{array}$ & n.a. & n.a. & n.a. & n.a. & n.a. & $\begin{array}{c}1.5 \pm \\
0.3\end{array}$ & $\begin{array}{c}0.5 \pm \\
0.1\end{array}$ & n.a. \\
\hline
\end{tabular}

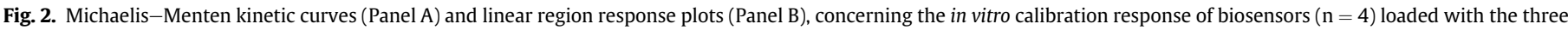

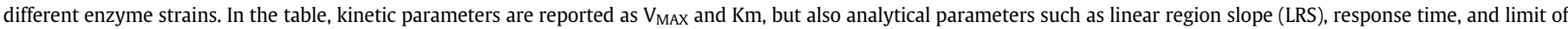

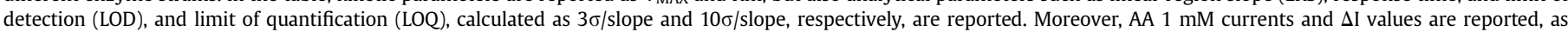

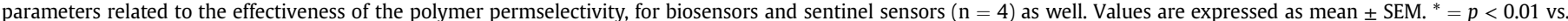
Hansenula polymorpha and Candida boidinii strains. n.a.: (data) not available.

were exposed to different concentrations of AA ranging from 0 to $1 \mathrm{mM}$ by means of additions of known volumes of AA stock solution (100 mM).

All the biosensors, as well as the sentinel sensors, were exposed to other different compounds, such as UA, DOPAC, DA, and 5-HIAA, representing other important interfering molecules. The abovementioned compounds did not produce any interference on the ethanol biosensor signal (data not shown), as previously shown (Calia et al., 2009; Puggioni et al., 2019).

Telemetric device construction and microvibration sensor integration

In the present study, a biotelemetric device (Fig. 3), as previously described (Rocchitta, Secchi, et al., 2013), was used. All the electronic components were purchased from Farnell-In-One Spa (Milan, Italy). In brief, the radio transceiver and the antenna were contained in an eZ430-RF2500 from Texas Instruments, Inc. (TI; Dallas, Texas, United States). The biotelemetric device comprised an amperometric section that consisted of a quad single-supply operational amplifier MCP6044 (Microchip Technology Inc.; Chandler, Arizona, United States) and a ZXRE4001 zener diode (Zetex; Manchester, United Kingdom). The analog-to-digital converter (ADC) was a basic component of the microcontroller (MSP430F2274, TI) in use in this system, while the 2.4-GHz transmitter was a TI CC2500. Moreover, the eZ430-RF2500 kit contained a serial-to-USB converter. In the present study, we have used a movement sensor (model MVS0608.02; Sensolute; Karlsruhe, Germany), represented by an omnidirectional microvibration sensor, with sensitivity autonomous from the orientation of the sensor and totally suitable for motion detection. The microvibration sensor registers motion and vibrations by means of a gold-plated, moving microball, with a diameter of $0.8 \mathrm{~mm}$, positioned in a hollow gold-plated cylinder and able to move freely inside: all the movements or vibrations, even the smallest, induce the ball to move so as to open or close gold-plated contacts. Due to its small dimensions $(2.85 \times 2.45 \times 1.7 \mathrm{~mm})$, the microvibration sensor is proper for very small electronic devices; in fact, it was directly soldered onto the surface of the eZ430-RF2500 board.

Resistors were made of metal oxide thick film ( $250 \mathrm{~mW}, 0.1 \%$ tolerance; Ohmite; Rolling Meadows, Illinois, United States), while capacitors were NP0-type multilayer ceramic (low-pass filter, decoupling). All the parts were soldered on dual-side printed circuit boards (PCB) produced as previously described (Rocchitta, Secchi, et al., 2013). A 100-mA-hour, 3-V lithium coin battery (Energizer CR2016) was used in order to supply power to the device for about 48 hours in continuous transmission $(0.12 \mathrm{~Hz})$.

\section{Induction to voluntary ethanol consumption}

The ethanol group $(n=4)$ was exposed to a period of induction to ethanol consumption. During the acquisition phase, each animal 


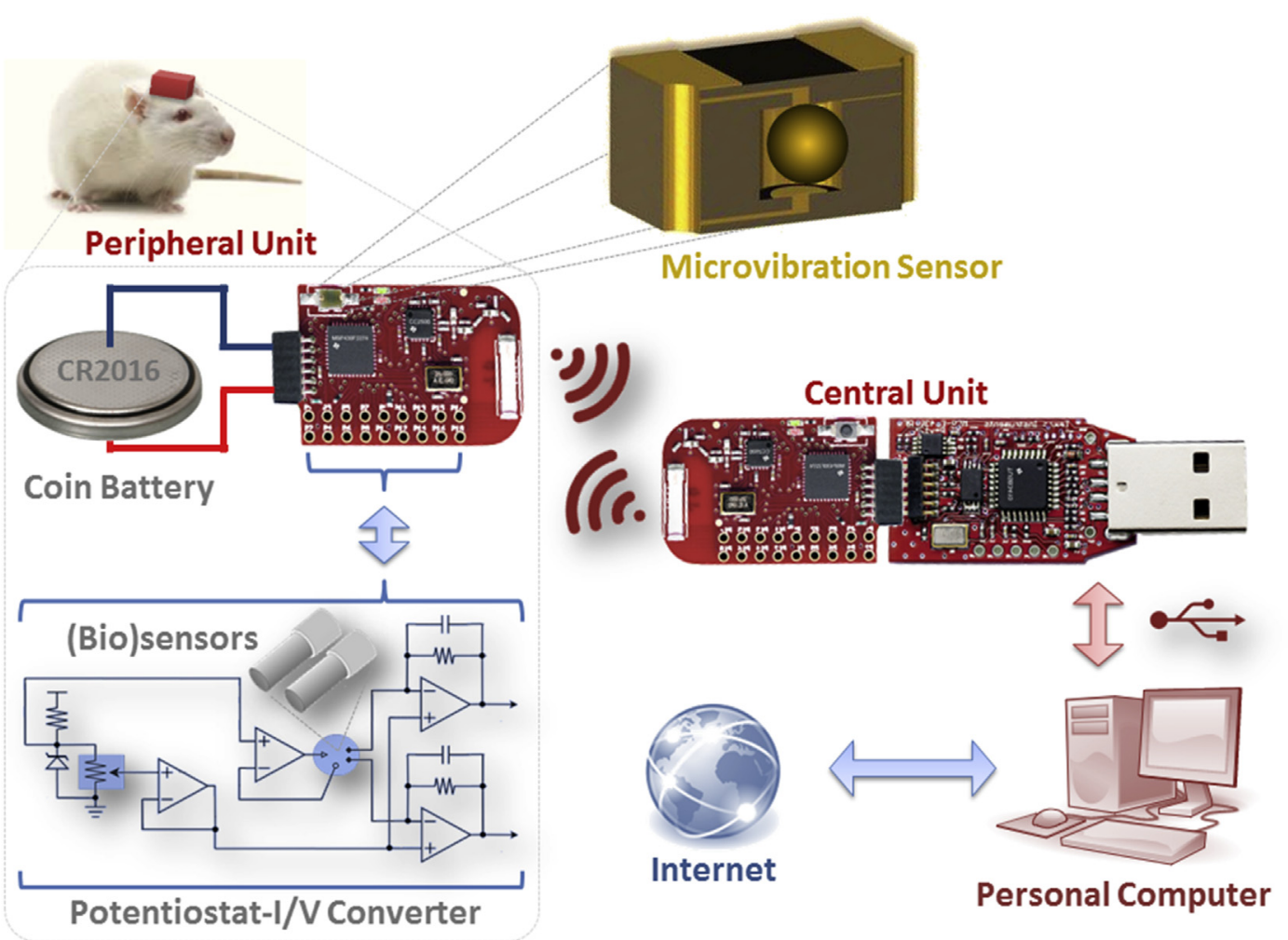

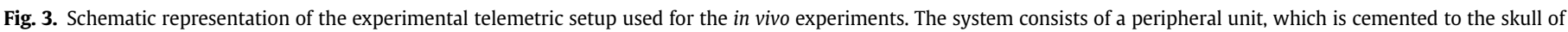

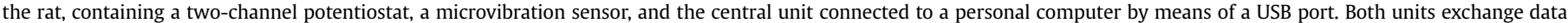
packets at $2.4 \mathrm{GHz}$ with a sample rate of $0.12 \mathrm{~Hz}$.

was housed individually. The procedure was carried out according to the protocol of free-choice ethanol consumption that consists of placing one bottle containing only tap water and another containing an appropriate ethanol solution, to which rats had free access. The initial ethanol concentration of $2 \% \mathrm{v} / \mathrm{v}$ was increased by $2 \%$ each day up to a final concentration of $10 \% \mathrm{v} / \mathrm{v}$ (5th day). Subjects were exposed to the free-choice protocol every day for 24 hours, and the $10 \%$ ethanol concentration remained constant during the following 2 weeks to establish baseline consumption $(5+14$ days). Standard food pellets were made available throughout the experiments. The control group $(n=4)$ was provided with food and two bottles of tap water for each rat and for an identical time period. Clean bottles containing freshly made ethanol solutions and tap water were provided daily to both the ethanol and the control groups. Bottle location was alternated for the ethanol group to prevent side preference. Ethanol consumption was calculated as $\mathrm{g} / \mathrm{kg}$ of body weight for each day and then the average was calculated (induction phase). After 2 weeks of induction, daily ethanol intake (expressed as grams, \pm SEM) at baseline was $3.49 \mathrm{~g} / \mathrm{kg} /$ body weight \pm 0.76 . This procedure was applied to accustom the rats to ethanol intake.

\section{Stereotaxic surgery and in vivo experimental procedures}

After 19 consecutive days of induction to voluntary ethanol or tap water intake, rats ( $\mathrm{n}=4$ /group) were anesthetized with ethylurethane and alpha chloralose $(1 \mathrm{~g} / \mathrm{kg}$ and $40 \mathrm{mg} / \mathrm{kg}$, intraperitoneally [i.p.], respectively) and placed into a stereotaxic apparatus (Stoelting; United States). Surgical procedures were conducted as previously described (Bazzu et al., 2009; Calia et al., 2009), maintaining the body temperature at $37^{\circ} \mathrm{C}$ by means of an isothermal heating pad. An incision (15-20 mm) was made in the skin over the skull, and the wound margin was infiltrated with lidocaine (3\%).
Two guide cannulas (320 microns outer diameter) were implanted in the left or right AcbSh using the following coordinates: A/ P: $+1.7 \mathrm{~mm}$ from bregma; M/L: $\pm 0.9 \mathrm{~mm}$ from bregma; $\mathrm{D} /$ $\mathrm{V}:-7.6 \mathrm{~mm}$ from the dura) according to the rat brain stereotaxic atlas of Paxinos and Watson (1998). Guide cannulas used for in vivo implantation were manufactured as previously described (Bellesi, Tononi, Cirelli, \& Serra, 2016; Bourdon et al., 2018) and suitably modified using polymide tubing (Nordson Medical; Galway, Ireland) with an internal diameter of $0.178 \mathrm{~mm}$ and an outer diameter of $0.216 \mathrm{~mm}$. Briefly, a length of a $10-\mu \mathrm{L}$ micropipette tip $(8 \mathrm{~mm})$ was sealed with epoxy glue to a portion of polymide tubing (7 mm). Then, a dummy cannula was made by combining a length of a $10-\mu \mathrm{L}$ micropipette tip $(8 \mathrm{~mm})$ with a portion of $\mathrm{Pt} / \mathrm{Ir}$ wire (0.175 mm outer diameter, Teflon ${ }^{\circledR}$-coated, $17 \mathrm{~mm}$ in length) covered with a small drop of glue in the tip.

Auxiliary and pseudo-reference $(\mathrm{Ag} / \mathrm{AgCl}$ wire) electrodes, both obtained from a 2-cm long silver wire, were inserted in the left parietal cortex, with the aid of two screws inserted into the skull for supporting the device adhesion (Rocchitta, Secchi, et al., 2013). A portion of the device (deprived of the battery) was fixed using dental adhesive to the skull (Paladur, Heraeus Kulzer, GmbH) as previously described (Bazzu et al., 2009; Rocchitta, Secchi, et al., 2013).

Half an hour before anesthesia and five consecutive days after surgery, rats were administered ceftazidime $(2.84 \mathrm{mg} / \mathrm{kg} / \mathrm{mL}$, i.p.). Following surgery, rats were allowed to drink a solution containing sucrose and analgesics (sucrose $5 \mathrm{~g}$; codeine $3 \mathrm{mg}$, and paracetamol $50 \mathrm{mg}$ in $100 \mathrm{~mL}$ of tap water) ad libitum for four consecutive days, and housed individually in environmentally enriched rectangular transparent plastic cages $(25 \times 25 \times 20 \mathrm{~cm})$ with free access to food, located side by side in order to prevent the influence of isolation on performance. 
Six days after the surgery, biosensor and sentinel sensors were made, calibrated in vitro, and inserted into the implanted cannulas and connected (together with the pseudo-reference and auxiliary sensors) to the biotelemetric device containing the microvibration sensor. The device was then affixed to the skull and the oxidation potential was applied to the biosensor and the sentinel sensor. The in vivo experiments started seven days after surgery, and each animal was located in a hemisphere-shaped chamber in order to permit free movement and reduce handling or other forms of stress (Bazzu et al., 2009; Calia et al., 2009).

During the experiments, rats of the ethanol group had only the bottle of $10 \%$ ethanol solution; rats of the control group were provided with one bottle of tap water.

\section{Histology}

The total number of animals used $(n=4+4)$ represents the number of animals that finished the experimental protocol and showed a correct cannula placement. At the end of the experimental recordings, all rats were euthanized for brain removal using sodium pentobarbitone (20\%) at the dose of $140 \mathrm{mg} / \mathrm{kg} / \mathrm{mL}$. Brains were frozen and $40 \mu \mathrm{m}$-thick coronal sections were obtained using a cryostat. Sections were used for the verification of the biosensors and the sentinel sensor placements. Based on histological analysis, no rats were excluded from the present study.

\section{Statistics}

Biosensors. Concentrations of ethanol and AA were expressed as millimoles per liter ( $\mathrm{mM}$ ), while oxidation currents were expressed as nanoamperes and reported as sentinel-subtracted and baselinesubtracted $(\Delta \mathrm{nA})$ raw data. After in vitro calibrations, biosensor currents were plotted versus ethanol concentrations, and a nonlinear fitting with the Michaelis-Menten equation was carried out on the entire concentration range $(0-170 \mathrm{mM})$ to evaluate analytical parameters as $\mathrm{V}_{\mathrm{MAX}}$ and $\mathrm{K}_{\mathrm{M}}$, while linear regressions were calculated at low concentrations $(0-25 \mathrm{mM})$.

The $A A \Delta I$ value represents the difference between the currents resulting from $1 \mathrm{mM}\left(\mathrm{AA} \mathrm{I}_{\lim }\right.$ ) and $0.5 \mathrm{mM}$ concentrations of $\mathrm{AA}$ in the electrochemical cell, as previously published (Rocchitta et al., 2012). It highlights the capability of PPD polymer to counteract the physiological fluctuations of AA and the currents derived from these. The limit of detection (LOD) and limit of quantification (LOQ) were calculated using a classical statistical method based on the standard deviation $(\sigma)$ of the response and the linear region slope of the calibration curve (ICH Harmonised Tripartite Guideline, 2005).

All data were expressed as mean \pm SEM, and statistical significance ( $p$ values) within each group was calculated by means of ANOVA by GraphPad Prism 5.02 v software.

Microvibration sensors. Microvibration data were shown as absolute values representing the sum of microvibrations per second (mv/sec). In addition, movement data were plotted as point-bypoint calculated differences of microvibrations $(\Delta)$ between ethanol and control groups and were expressed as mean \pm SD. Moreover, the differential area under the curve $(\triangle A U C)$ was obtained by integrating the number of microvibrations $(\Delta)$ in a 15minute period. Statistical significance ( $p$ values) among groups was calculated by means of ANOVA by GraphPad Prism $5.02 \mathrm{v}$ software.

\section{Results}

In vitro biosensor and sentinel sensor performance

All biosensor designs were tested in vitro. Implantable sensors were tested the day before the in vivo experiments. In particular, biosensors were compared for responses to ethanol, in terms of kinetic parameters as $\mathrm{V}_{\mathrm{MAX}}$ and $\mathrm{K}_{\mathrm{M}}$, but also in terms of other analytical parameters such as LRS, LOD, and LOQ. Moreover, AA permselectivity and response time were evaluated. Furthermore, responses for different enzyme strains were compared (Fig. 2).

As previously published (Rocchitta et al., 2012), the chosen biosensor design used for in vitro calibration and in vivo implantation was $\mathrm{Pt}_{\mathrm{c}} / \mathrm{PPD} /[\{\mathrm{PEI}(1 \%)+\mathrm{Glyc}(1 \%)\} / \mathrm{AOx}]_{10} / \mathrm{PU}(1 \%)$, and the corresponding sentinel microsensor. In agreement with previously published data (Rocchitta et al., 2012), the biosensor loading $H$. polymorpha strain gave a good response in terms of $\mathrm{V}_{\mathrm{MAX}}$ and $\mathrm{K}_{\mathrm{M}}$ $\left(130.31 \pm 12.35 \mathrm{nA}\right.$ and $40.72 \pm 11.57 \mathrm{mM}$, respectively; $\left.\mathrm{R}^{2}=0.996\right)$ and LRS $\left(1.98 \pm 0.07 \mathrm{nA} / \mathrm{mM} ; \mathrm{R}^{2}=0.989\right)$, while the response to $1 \mathrm{mM}$ AA was $1.61 \pm 0.41 \mathrm{nA}$ with a $\Delta \mathrm{I}$ of $0.51 \pm 0.11 \mathrm{nA}\left(\mathrm{R}^{2}=0.991\right)$. The above-mentioned biosensor design showed acceptable LOD and LOQ values $(0.11 \pm 0.04 \mathrm{mM}$ and $0.33 \pm 0.12 \mathrm{nA}$, respectively) and response time $\left(1.52 \pm 0.85 \mathrm{sec} ; \mathrm{R}^{2}=0.990\right)$.

The biosensor design loading AOx from the $C$. boidinii strain gave results comparable to the previous one in terms of $\mathrm{V}_{\mathrm{MAX}}$ and $\mathrm{K}_{\mathrm{M}}$ $\left(100.53 \pm 10.71 \mathrm{nA}\right.$ and $47.96 \pm 11.44 \mathrm{mM}$, respectively; $\left.\mathrm{R}^{2}=0.990\right)$, LOD and LOQ $(0.16 \pm 0.64 \mathrm{mM}$ and $47.96 \pm 11.44 \mathrm{mM}$, respectively; $\left.\mathrm{R}^{2}=0.998\right)$, while showed a slight decrease in terms of LRS $\left(1.38 \pm 0.04 \mathrm{nA} / \mathrm{mM} ; \mathrm{R}^{2}=0.988\right), \mathrm{AA} \mathrm{I}_{\mathrm{lim}}$ and $\Delta \mathrm{I}(1.35 \pm 0.53 \mathrm{nA}$ and $0.42 \pm 0.13 \mathrm{nA}$, respectively). Moreover, this design showed a slight increase in terms of response time $\left(1.9 \pm 0.73 \mathrm{sec} ; \mathrm{R}^{2}=0.997\right)$ when compared with the biosensor loading AOx from the H. polymorpha strain. Overall, the biosensor loading $C$. boidinii resulted in its performances being not statistically different from the $H$. polymorpha one.

The loading of AOx from the P. pastoris strain led to a substantial improvement in the performances of the biosensor, when compared with previous designs. In fact, $\mathrm{V}_{\operatorname{MAX}}(375.62 \pm 13.15 \mathrm{nA}$; $\left.\mathrm{R}^{2}=0.995\right)$ was considerably greater $(p<0.01)$, while $\mathrm{K}_{\mathrm{M}}$ $\left(28.03 \pm 3.31 \mathrm{nA} ; \mathrm{R}^{2}=0.995\right)$ resulted significantly smaller $(p<0.01)$ when compared with biosensors loaded with the AOx derived from the $H$. polymorpha and $C$. boidinii strains. LRS $\left(7.57 \pm 0.12 \mathrm{nA} / \mathrm{mM} ; \mathrm{R}^{2}=0.987\right)$ underwent the most significant increase, of about 3.8 times vs. $H$. polymorpha strain $(p<0.01)$, and about 5.5 times vs. the $C$. boidinii strain $(p<0.01)$. Even LOD and LOQ $(0.05 \pm 0.0 .03 \mathrm{mM}$ and $0.15 \pm 0.07 \mathrm{mM}$, respectively; $\left.\mathrm{R}^{2}=0.991\right)$ resulted significantly lower $(p<0.01)$. The remaining parameters of $\mathrm{AA}_{\mathrm{lim}}, \Delta \mathrm{I}$, and response time $(1.44 \pm 0.35 \mathrm{nA}$ $0.33 \pm 0.15 \mathrm{nA}$ and $1.12 \pm 0.47 \mathrm{~s}$, respectively) did not show substantial differences $(p>0.05)$.

In terms of AA response, sentinel sensors did not significantly differ from relative biosensors. In fact, when exposed to the same AA concentrations as the relative biosensors' group, showed comparable shielding capabilities in terms of $A A_{\text {lim }}$ and $\Delta \mathrm{I}$ : $1.53 \pm 0.28 \mathrm{nA}$ and $0.46 \pm 0.14 \mathrm{nA}$, respectively $(\mathrm{n}=4 ; p>0.05)$.

\section{In vivo biosensor response}

Because of its better in vitro performance, the biosensor design loading $P$. pastoris strain was selected for in vivo implantation in the AcbSh. Seven days after cannula placement, biosensors and sentinels were manufactured and calibrated, exposed to ethanol and AA 
solutions, and then inserted in the AcbSh through the cannula. The in vivo experiment started 24 hours after the insertion by applying the anodic potential of $+700 \mathrm{mV}$ and recording the current signal until a steady baseline was obtained (panel A of Fig. 4 shows the last 30 minutes). In the control group (blue curve, Fig. 4), animals $(\mathrm{n}=4)$ were allowed to access the tap water bottle for 15 minutes. In this group, no current changes were detected. Subjects $(n=4)$ in the ethanol group (red curve, Fig. 4) after baseline stabilization were allowed to access the $10 \%$ ethanol solution for 15 minutes. In this group, the biosensor's current increased to $26.72 \pm 0.224 \mathrm{nA}$ about 30 minutes after starting ethanol intake, returning to baseline values after about 120 minutes. As shown in panel B of Fig. 4, the ethanol current (red column), detected 15 minutes after the ethanol intake, reached the maximum amplitude and was significantly higher $(p<0.001)$ than the controls (blue column).

The LRS was calculated through the current values of the in vitro calibrations, which was shown to be equal to $7.57 \pm 0.12 \mathrm{nA} / \mathrm{mM}$. Therefore, the maximal concentration of extracellular ethanol was found to be around $3.53 \mathrm{mM}$.
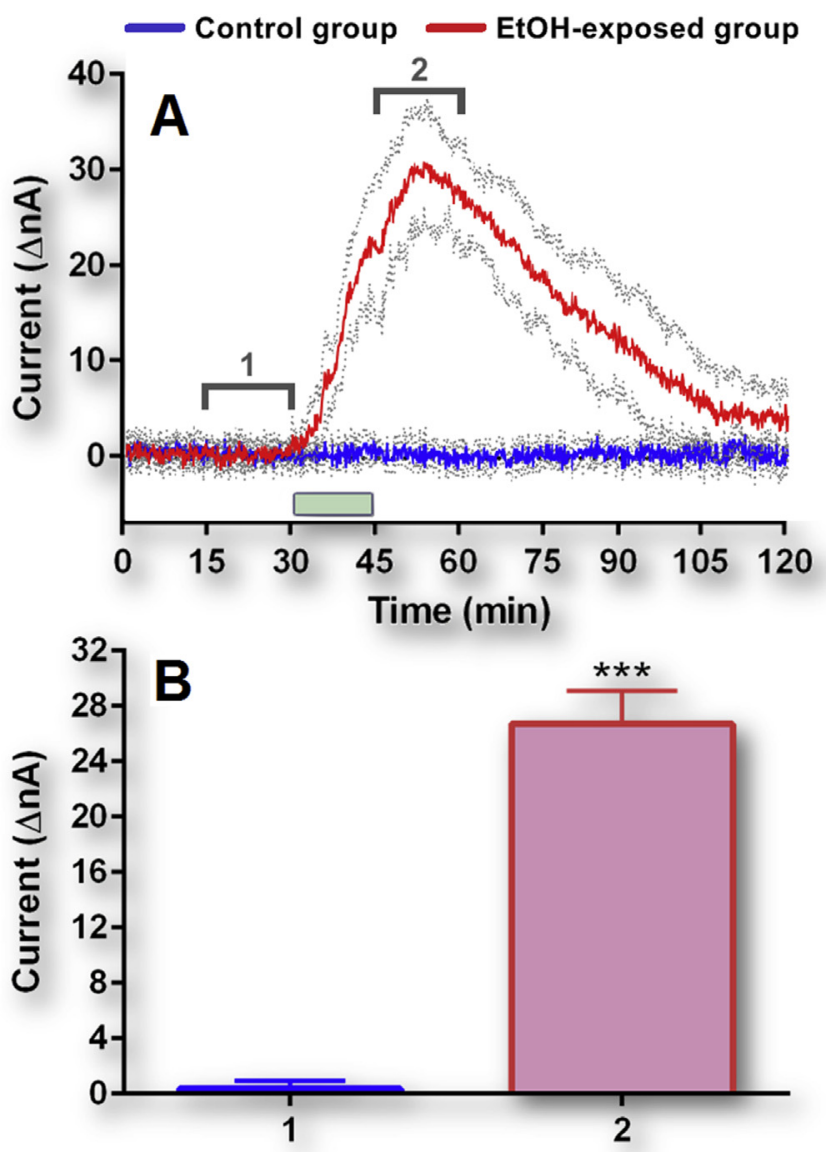

Fig. 4. In vivo response of biosensor implanted in the right nucleus accumbens shell after voluntary intake of tap water or $10 \%$ ethanol solution. The chosen biosensor design, $\mathrm{Pt}_{\mathrm{c}} / \mathrm{PPD} /[\{\mathrm{PEI}(1 \%)+\text { Glyc }(1 \%)\} / \mathrm{AOx}]_{10} / \mathrm{PU}(1 \%)$, was prepared, calibrated in vitro, and inserted immediately after calibration (day 0-28). The day after the implant, the potential was applied to the biosensor and sentinel and the experiments were performed. In panel $A$, the blue curve represents the mean \pm SD of current responses (biosensor-sentinel signals) in the control group, while the red curve shows the mean \pm SD of the biosensor-sentinel responses in the ethanol-exposed group. After having reached a stable baseline, rats were allowed access to tap water (control group) or $10 \%$ ethanol solution (EtOH-exposed group), respectively, for 15 minutes. Panel B shows the highest detected ethanol current (2) compared to the respective baseline, analyzed by means of a paired $t$ test $(p<0.001)$. Each column was obtained by integrating the currents in a 15-minute window before (1) and after (2) ethanol intake. (For interpretation of the references to color in this figure legend, the reader is referred to the Web version of this article.)
After these experiments, rats were sacrificed with anesthetic, in order to perform post mortem histology to verify the location of biosensors in the AcbSh, which confirmed that all the biosensors were located in the correct position (data not shown).

Effect of ethanol intake on animals' motion through the microvibration sensor data analysis

The animals' microvibrations (Fig. 5), expressed as the number of microvibrations per second, were monitored during baseline recording for assessment of ethanol concentration as well as during and after tap water (control group, panel A) or ethanol intake (ethanol group, panel B). As can be seen in Fig. 5, baseline levels of microvibrations were recorded for 30 minutes before rats' exposure to tap water (panel A) or $10 \%$ ethanol solution (panel B). At the beginning (before tap water or ethanol intake), higher motion intensity was detected when the animals were settled in the experiment bowl, due to the exploration of the new environment (Fig. 5, panels A and B). As shown in panel A of Fig. 5, the average number of microvibrations for the control group was quite constant $(65 \pm 7$ $\mathrm{mv} / \mathrm{s}$ ). As shown in panel B of Fig. 5, the number of microvibrations per second significantly increased about 45 minutes after ethanol exposure, settling around an average number of $122 \pm 13 \mathrm{mv} / \mathrm{sec}$.

As shown in Fig. 6, the point-by-point calculation of the differences of microvibrations $(\Delta)$ between the control and ethanol
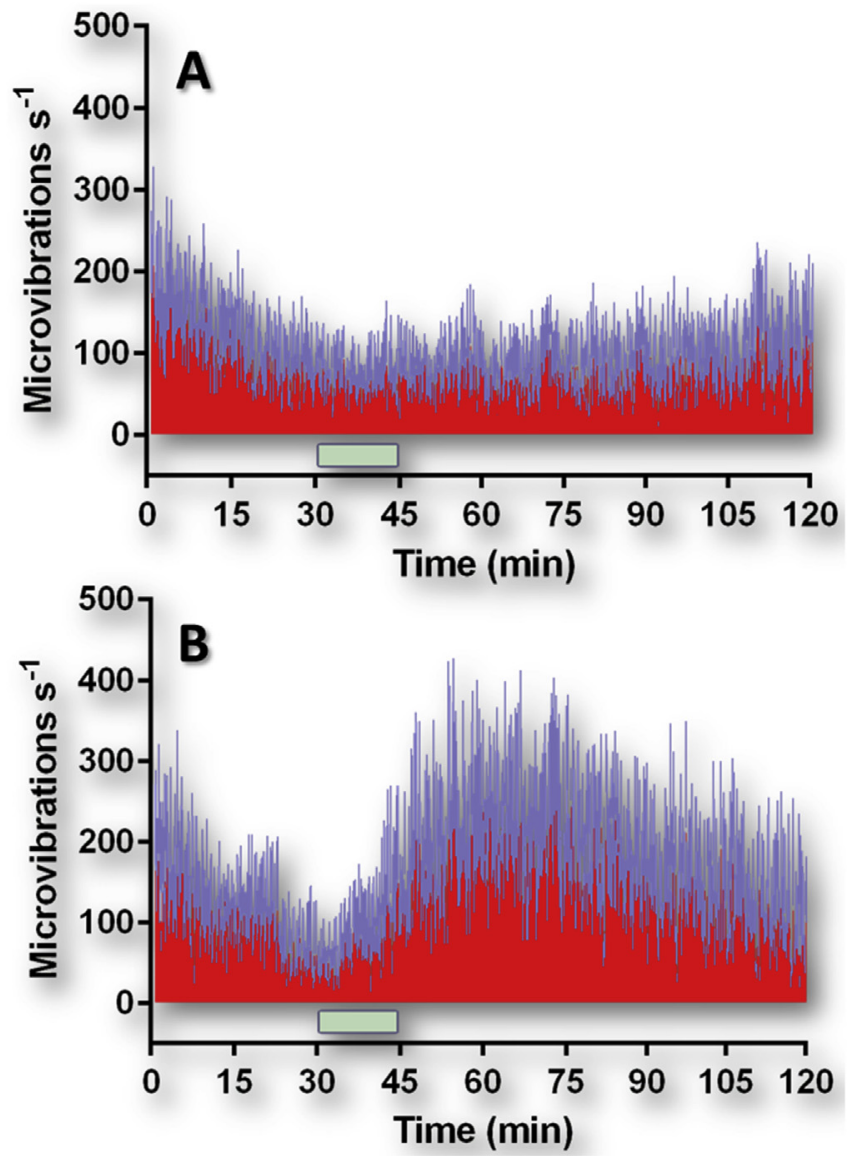

Fig. 5. Representative graphs showing the number of microvibrations per second during baseline recordings, and during and after tap water (panel A, control group) or ethanol intake (panel B, ethanol-exposed group). The data are given as mean (red bars) $\pm S D$ (gray bars) of microvibrations per second, calculated starting from wireless data packets. (For interpretation of the references to color in this figure legend, the reader is referred to the Web version of this article.) 


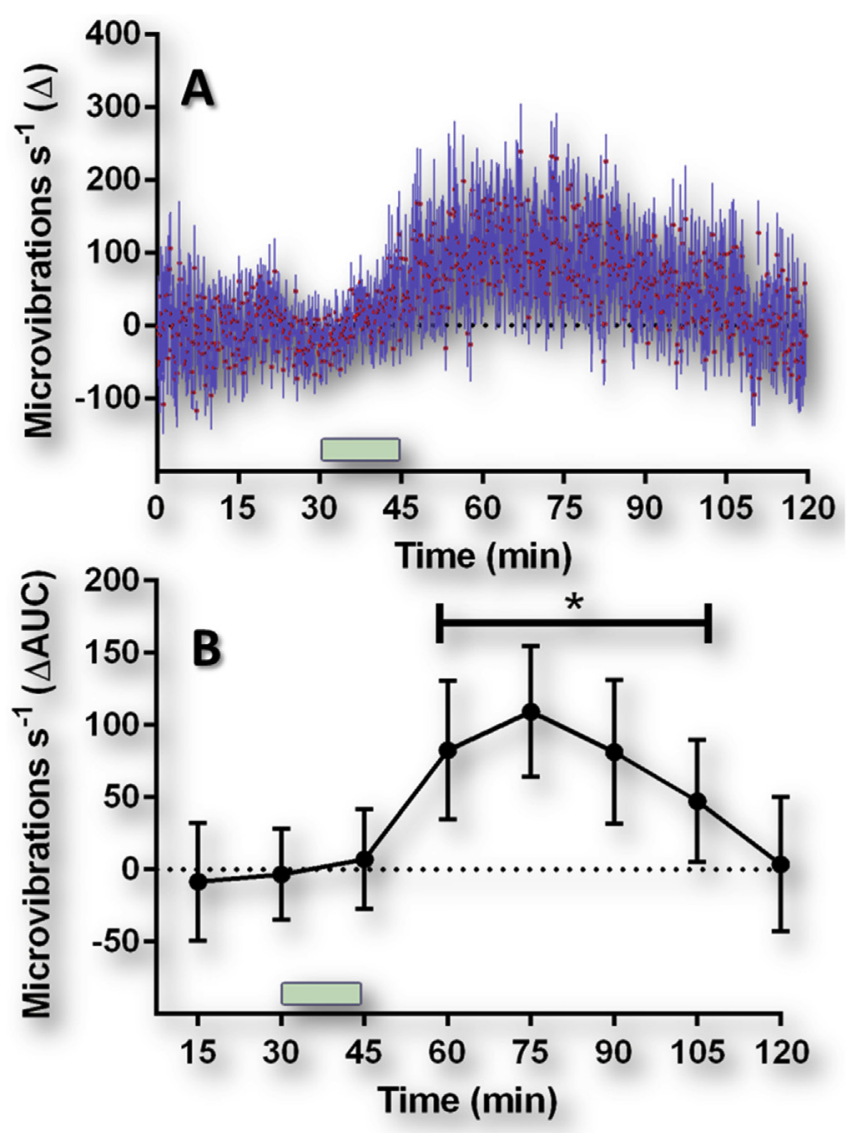

Fig. 6. The plot in panel A shows the point-by-point calculated differences of microvibrations $(\Delta)$ between tap water-exposed and ethanol-exposed groups, expressed as mean $\pm S D$. In panel $B$, the differential area under the curve $(\triangle A U C)$, obtained by the integration of the above-mentioned differences, demonstrated a significant increase of the $\Delta$ after ethanol intake ( $p<0.001$ vs. pre-exposure points). In the plot, each point (given as mean $\pm \mathrm{SD}$ ) has been obtained by integrating the number of microvibrations $(\Delta)$ in a 15 -minute period.

groups demonstrated a significant increase in animals' motion about 45 minutes after ethanol intake (Fig. 6, panel A). This result appears clearer when data, obtained by the above-mentioned differences, were integrated in a 15 -minute period and plotted as the differential area under the curve ( $\Delta$ AUC) as shown in Fig. 6, panel B.

\section{Discussion}

The present study describes a series of experiments aimed at validating the application of a novel dual telemetric device, characterized by an implantable enzymatic biosensor for the real-time amperometric detection of extracellular ethanol concentrations in a discrete brain region and a movement sensor (microvibration sensor), to simultaneously detect rats' microvibrations. This device allows us, for the first time, to highlight in real time the amount of ethanol drunk by the rat and to correlate ethanol concentration, measured by the biosensor in the brain, with the animals' movements. Moreover, the same device allows one to further elucidate the pharmacokinetic and the toxicokinetic effects of ethanol, which still need to be better understood, in particular in the case of voluntary ethanol intake. To achieve this aim, we initially tested the efficiency of AOx derived from $C$. boidinii and P. pastoris yeast strains, different with respect to that used ( $H$. polymorpha) in our previous reports (Rocchitta et al., 2012; Secchi et al., 2013). Interestingly, we found that loading biosensors with AOx derived from
C. boidinii resulted in overlapping performances with respect to those derived from $H$. polymorpha. In contrast, AOx obtained by $P$. pastoris provided a considerable improvement of biosensor performances in terms of kinetic parameters, according to the Michaelis-Menten curve $\left(\mathrm{V}_{\mathrm{MAX}} \mathrm{K}_{\mathrm{M}}\right)$ and in terms of sensitivity (LRS). In fact, the $\mathrm{V}_{\mathrm{MAX}}$ of the enzyme obtained from P. pastoris was about three times greater than the $\mathrm{V}_{\mathrm{MAX}}$ of $\mathrm{AOx}$ from $C$. boidinii and $H$. polymorpha. This reveals the remarkable efficiency of the enzyme for the conversion of ethanol and the sensitivity of the biosensor reflected in the LRS, that is, the parameter expressing the slope of the linear region that corresponds to the angular coefficient of the portion of the Michaelis-Menten curve, which provides, in analytical terms, a measure of the sensitivity of the biosensor. Moreover, the AOx derived from $P$. pastoris showed an LRS of $7.57 \pm 0.12$, a value 4 to 5 times greater than that obtained for the LRS of the $H$. polymorpha and $C$. boidinii, respectively. Consequently, since the design of the biosensor containing the AOx derived from $P$. pastoris proved to be the most efficient, it was considered suitable for further testing in vivo.

In the present study, we were able to correlate the amount drunk by each rat with the amount of ethanol measured in the AcbSh. As expected from the in vitro assays, the in vivo kinetic results from the biosensor loaded with AOx from the P. pastoris disclosed that this biosensor could detect the rise of ethanol in the AcbSh after 15 minutes of voluntary 10\% ethanol intake (Fig. 4). These results are in agreement with those reported from our previous study (Rocchitta et al., 2012), in which biosensors detected a single peak resulting from the non-contingent administration of ethanol ( $1 \mathrm{~g} / \mathrm{kg} / 1.5 \mathrm{~mL}$, intragastrically [i.g.]). Moreover, the concentration of ethanol detected in the AcbSh by current data is congruent with what is reported in the literature, after correction for amount of ethanol and sampling time (Schier, Mangieri, Dilly, \& Gonzales, 2012).

In our experiments, rats were allowed to drink $10 \%$ ethanol solution for 15 minutes, and they consumed approximately $1.15 \pm 0.12 \mathrm{~mL} / \mathrm{kg}$, resulting in a brain ethanol concentration of $0.385 \pm 0.039 \mathrm{~g} / \mathrm{kg}$, which is about 2.6 times lower with respect to that obtained after an intragastric dose of ethanol $(1 \mathrm{~g} / \mathrm{kg}$; Rocchitta et al., 2012). The main striking difference between these two modalities of oral administration of ethanol is that in our previous study ethanol was administered in a single bolus (Rocchitta et al., 2012). Thus, based on purely theoretical calculations, the maximum ethanol concentration in the extracellular space of the AcbSh after the non-contingent single bolus administration of $1 \mathrm{~g} /$ $\mathrm{kg}$ of ethanol should have been around $5.4 \mathrm{mM}$ against the recorded concentration of $3.5 \mathrm{mM}$. In this experiment, we had animals voluntarily consuming ethanol with a modality of freely on-going drinking during 15 minutes, in which each rat slowly sips.

Moreover, in the present study, in addition to being able to record the kinetics of AcbSh extracellular ethanol concentrations, due to the changes of the current derived from the oxidation of ethanol, we have also been able to evaluate the microvibrations, and expression of the ethanol-elicited motor behavioral response in freely moving rats (Rocchitta, Secchi, et al., 2013). Accordingly, the microvibrations could be indicative of the overall locomotor activity in rats, as reported by our research group in a previous work (Rocchitta, Secchi, et al., 2013). Notably, both recordings from the biosensor and the microvibration sensor described, although with different time-dependencies, similar U-shaped curves. In particular, the effect of ethanol on microvibrations appeared delayed with respect to the signal originating from ethanol voluntary intake, as shown in Figs. 4 and 6, which clearly display timedistinguished peaks delay of AcbSh ethanol concentrations and of microvibrations after ethanol intake. Moreover, the observation that the increase in microvibrations, which returns to baseline 
levels approximately 120 minutes after drinking, supports the suggestion that low doses of ethanol (well in the range of those assumed on average by rats of the ethanol group) could determine an increase in movement in the animals (Martí-Prats et al., 2013). Interestingly, in this regard, we speculate that this delay could be due to the possible metabolism of ethanol to acetaldehyde (Correa et al., 2012; Peana et al., 2017), involved in the stimulant and locomotors effects of ethanol (Martí-Prats et al., 2013), although this method does not allow such an interpretation.

In summary, with the application of this innovative type of biosensor and microvibration sensor, we were able to disclose the kinetic relationship between ethanol consumption, ethanol concentrations in the AcbSh, and ethanol-stimulated motor behavior. Moreover, these devices appear particularly promising for implantation in other brain areas for the real-time managing of tissue ethanol concentrations and behavior that could be of great interest, particularly in studies devoted to characterizing the relationship between ethanol-induced motor activity (Sánchez-Catalán et al., 2009), reward (Ikemoto, 2010), and motivation (Camarini et al., 2010). In addition, given the critical role of dopamine transmission in the AcbSh in motivated behaviors, the application of this technology might also be combined with the real-time detection of ethanol-induced dopamine release (Imperato \& Di Chiara, 1986) by means of ultra microsensors and fast-scan cyclic voltammetry (Rose, Karkhanis, Steiniger-Brach, \& Jones, 2016).

\section{Conclusion}

Overall, the results of this study demonstrate the feasibility and highly promising combined application of a high sensitivity and high temporal resolution ethanol biosensor (the most performing biosensor at the time of the submission of the present study), and of a microvibration sensor. Additionally, the combination of the biosensor with the microvibration sensor is innovative and may be helpful in giving synchronized information about neurochemistry and animal motion. In other words, this application allows relating, in freely moving rats voluntarily taking ethanol, the kinetic relationship between tissue concentrations of ethanol and ethanolinduced motor response. In conclusion, although the development of a feasible biosensory technology for the in vivo detection of ethanol is at its beginning, the evidence provided here clearly depicts this approach as having great technological and investigational potential.

\section{Conflict of interest}

G. Rocchitta, A. T. Peana, G. Bazzu, A. Cossu, S. Carta, P. Arrigo, A. Bacciu; R. Migheli, D. Farina, M. Zinellu, E. Acquas, and P. A. Serra declare that there is no commercial conflict of interest regarding the publication of this article.

\section{Acknowledgments}

This research was supported by funds from Fondazione di Sardegna 2013 (Sassari, Italy), awarded to A.T. Peana.

\section{References}

Addicott, M. A., Marsh-Richard, D. M., Mathias, C. W., \& Dougherty, D. M. (2007). The biphasic effects of alcohol: Comparisons of subjective and objective measures of stimulation, sedation, and physical activity. Alcoholism: Clinical and Experimental Research, 31, 1883-1890. https://doi.org/10.1111/j.15300277.2007.00518.x.

Bassareo, V., Cucca, F., Frau, R., \& Di Chiara, G. (2017). Changes in dopamine transmission in the nucleus accumbens shell and core during ethanol and sucrose self-administration. Frontiers in Behavioral Neuroscience, 11, 71. https:// doi.org/10.3389/fnbeh.2017.00071.
Bazzu, G., Puggioni, G. G., Dedola, S., Calia, G., Rocchitta, G., Migheli, R., et al. (2009). Real-time monitoring of brain tissue oxygen using a miniaturized biotelemetric device implanted in freely moving rats. Analytical Chemistry, 81, 2235-2241. https://doi.org/10.1021/ac802390f.

Bellesi, M., Tononi, G., Cirelli, C., \& Serra, P. A. (2016). Region-specific dissociation between cortical noradrenaline levels and the sleep/wake cycle. Sleep, 39 143-154. https://doi.org/10.5665/sleep.5336.

Bourdon, A. K., Spano, G. M., Marshall, W., Bellesi, M., Tononi, G., Serra, P. A., et al. (2018). Metabolomic analysis of mouse prefrontal cortex reveals upregulated analytes during wakefulness compared to sleep. Scientific Reports, 8, 11225 https://doi.org/10.1038/s41598-018-29511-6.

Calia, G., Rocchitta, G., Migheli, R., Puggioni, G., Spissu, Y., Bazzu, G., et al. (2009). Biotelemetric monitoring of brain neurochemistry in conscious rats using microsensors and biosensors. Sensors, 9, 2511-2523. https://doi.org/10.3390/ s90402511.

Camarini, R., Pautassi, R. M., Méndez, M., Quadros, I. M., Souza-Formigoni, M. L., \& Boerngen-Lacerda, R. (2010). Behavioral and neurochemical studies in distinct animal models of ethanol's motivational effects. Current Drug Abuse Reviews, 3, 205-221.

Correa, M., Salamone, J. D., Segovia, K. N., Pardo, M., Longoni, R., Spina, L., et al. (2012). Piecing together the puzzle of acetaldehyde as a neuroactive agent. Neuroscience \& Biobehavioral Reviews, 36, 404-430. https://doi.org/10.1016/ j.neubiorev.2011.07.009.

Correa, M., Viaggi, C., Escrig, M. A., Pascual, M., Guerri, C., Vaglini, F., et al. (2009). Ethanol intake and ethanol-induced locomotion and locomotor sensitization in Cyp2e1 knockout mice. Pharmacogenetics and Genomics, 19, 217-225. https:// doi.org/10.1097/FPC.0b013e328324e726.

Di Chiara, G., Tanda, G., \& Carboni, E. (1996). Estimation of in-vivo neurotransmitter release by brain microdialysis: The issue of validity. Behavioural Pharmacology, 7, 640-657.

Fernández, M. S., Fabio, M. C., Miranda-Morales, R. S., Virgolini, M. B., De Giovanni, L. N., Hansen, C., et al. (2016). Age-related effects of chronic restraint stress on ethanol drinking, ethanol-induced sedation, and on basal and stressinduced anxiety response. Alcohol, 51, 89-100. https://doi.org/10.1016/ j.alcohol.2015.11.009.

Gilpin, N. W., \& Koob, G. F. (2008). Neurobiology of alcohol dependence: Focus on motivational mechanisms. Alcohol Research \& Health, 31, 185-195.

Gonzales, R. A., Job, M. O., \& Doyon, W. M. (2004). The role of mesolimbic dopamine in the development and maintenance of ethanol reinforcement. Pharmacology \& Therapeutics, 103, 121-146. https://doi.org/10.1016/j.pharmthera.2004.06.002.

Griffin, W. C., 3rd, Middaugh, L. D., \& Becker, H. C. (2007). Voluntary ethanol drinking in mice and ethanol concentrations in the nucleus accumbens. Brain Research, 1138, 208-213. https://doi.org/10.1016/j.brainres.2006.12.071.

Holdstock, L., \& de Wit, H. (1998). Individual differences in the biphasic effects of ethanol. Alcoholism: Clinical and Experimental Research, 22, 1903-1911.

ICH Q2 (R1), Harmonised Tripartite Guideline. (2005). Validation of analytical procedures: Text and methodology (pp. 11-12). https://www.ich.org/fileadmin/ Public_Web_Site/ICH_Products/Guidelines/Quality/Q2_R1/Step4/Q2_R1_ Guideline.pdf.

Ikemoto, S. (2010). Brain reward circuitry beyond the mesolimbic dopamine system: A neurobiological theory. Neuroscience \& Biobehavioral Reviews, 35, 129-150. https://doi.org/10.1016/j.neubiorev.2010.02.001.

Imperato, A., \& Di Chiara, G. (1986). Preferential stimulation of dopamine release in the nucleus accumbens of freely moving rats by ethanol. Journal of Pharmacology and Experimental Therapeutics, 239, 219-228.

Kennedy, R. T. (2013). Emerging trends in in vivo neurochemical monitoring by microdialysis. Current Opinion in Chemical Biology, 17, 860-867. https://doi.org/ 10.1016/j.cbpa.2013.06.012.

Kirwan, S. M., Rocchitta, G., McMahon, C. P., Craig, J. D., Killoran, S. J., O'Brien, K. B., et al. (2007). Modifications of poly(o-phenylenediamine) permselective layer on Pt-Ir for biosensor application in neurochemical monitoring. Sensors, 7, 420-437.

Martí-Prats, L., Sánchez-Catalán, M. J., Orrico, A., Zornoza, T., Polache, A., \& Granero, L. (2013). Opposite motor responses elicited by ethanol in the posterior VTA: The role of acetaldehyde and the non-metabolized fraction of ethanol. Neuropharmacology, 72, 204-214. https://doi.org/10.1016/j.neuropharm.2013.04.047.

Melendez, R. I., Hicks, M. P., Cagle, S. S., \& Kalivas, P. W. (2005). Ethanol exposure decreases glutamate uptake in the nucleus accumbens. Alcoholism: Clinical and Experimental Research, 29, 326-333.

Middaugh, L. D., Szumlinski, K. K., Van Patten, Y., Marlowe, A. L., \& Kalivas, P. W. (2003). Chronic ethanol consumption by C57BL/6 mice promotes tolerance to its interoceptive cues and increases extracellular dopamine, an effect blocked by naltrexone. Alcoholism: Clinical and Experimental Research, 27, 1892-1900. https://doi.org/10.1097/01.ALC.0000099264.36220.48.

Moghaddam, B., \& Bolinao, M. L. (1994). Biphasic effect of ethanol on extracellular accumulation of glutamate in the hippocampus and the nucleus accumbens. Neuroscience Letters, 178, 99-102.

Nie, Z., Madamba, S. G., \& Siggins, G. R. (1994). Ethanol inhibits glutamatergic neurotransmission in nucleus accumbens neurons by multiple mechanisms. Journal of Pharmacology and Experimental Therapeutics, 271, 1566-1573.

O'Neill, R. D., Rocchitta, G., McMahon, C. P., Serra, P. A., \& Lowry, J. P. (2008). Designing sensitive and selective polymer/enzyme composite biosensors for brain monitoring in vivo. TRAC Trends in Analytical Chemistry, 27, 78-88.

Paxinos, G., \& Watson, C. (1998). The rat brain in stereotaxic coordinates (4th ed.). San Diego, California: Academic Press. 
Peana, A. T., Sánchez-Catalán, M. J., Hipólito, L., Rosas, M., Porru, S., Bennardini, F., et al. (2017). Mystic acetaldehyde: The never-ending story on alcoholism. Frontiers in Behavioral Neuroscience, 11, 81. https://doi.org/10.3389/ fnbeh.2017.00081.

Puggioni, G., Calia, G., Arrigo, P., Bacciu, A., Bazzu, G., Migheli, R., et al. (2019). Lowtemperature storage improves the over-time stability of implantable glucose and lactate biosensors. Sensors, 19. https://doi.org/10.3390/s19020422. pii: E422.

Rocchitta, G., Bacciu, A., Arrigo, P., Migheli, R., Bazzu, G., \& Serra, P. A. (2018). Propylene glycol stabilizes the linear response of glutamate biosensor: Potential implications for in-vivo neurochemical monitoring. Chemosensors, 6, 58.

Rocchitta, G., Secchi, O., Alvau, M. D., Farina, D., Bazzu, G., Calia, G., et al. (2013). Simultaneous telemetric monitoring of brain glucose and lactate and motion in freely moving rats. Analytical Chemistry, 85, 10282-10288. https://doi.org/ 10.1021/ac402071w.

Rocchitta, G., Secchi, O., Alvau, M. D., Migheli, R., Calia, G., Bazzu, G., et al. (2012) Development and characterization of an implantable biosensor for telemetric monitoring of ethanol in the brain of freely moving rats. Analytical Chemistry, 84, 7072-7079. https://doi.org/10.1021/ac301253h.

Rocchitta, G. \& Serra, P. A. (2013). Direct monitoring of ethanol in the brain. OA Alcohol, 1, 15.

Rodd, Z. A., Bell, R. L., McKinzie, D. L., Webster, A. A., Murphy, J. M., Lumeng, L., et al. (2004). Low-dose stimulatory effects of ethanol during adolescence in rat lines selectively bred for high alcohol intake. Alcoholism: Clinical and Experimental Research, 28, 535-543.
Rose, J. H., Karkhanis, A. N., Steiniger-Brach, B., \& Jones, S. R. (2016). Distinct effects of nalmefene on dopamine uptake rates and kappa opioid receptor activity in the nucleus accumbens following chronic intermittent ethanol exposure. International Journal of Molecular Sciences, 17. https://doi.org/10.3390/ ijms17081216. pii:E1216.

Sánchez-Catalán, M. J., Hipólito, L., Zornoza, T., Polache, A., \& Granero, L. (2009) Motor stimulant effects of ethanol and acetaldehyde injected into the posterior ventral tegmental area of rats: Role of opioid receptors. Psychopharmacology 204, 641-653. https://doi.org/10.1007/s00213-009-1495-6.

Schier, C. J., Mangieri, R. A., Dilly, G. A., \& Gonzales, R. A. (2012). Microdialysis of ethanol during operant ethanol self-administration and ethanol determination by gas chromatography. Journal of Visualized Experiments, 5. https://doi.org/ 10.3791/4142. pii:4142.

Secchi, O., Zinellu, M., Spissu, Y., Pirisinu, M., Bazzu, G., Migheli, R., et al. (2013) Further in-vitro characterization of an implantable biosensor for ethanol monitoring in the brain. Sensors, 13, 9522-9535. https://doi.org/10.3390/ s130709522.

Tambour, S., Didone, V., Tirelli, E., \& Quertemont, E. (2006). Locomotor effects of ethanol and acetaldehyde after peripheral and intraventricular injections in Swiss and C57BL/6J mice. Behavioural Brain Research, 172, 145-154. https:// doi.org/10.1016/j.bbr.2006.05.010

Weiss, F., Lorang, M. T., Bloom, F. E., \& Koob, G. F. (1993). Oral alcohol selfadministration stimulates dopamine release in the rat nucleus accumbens: Genetic and motivational determinants. Journal of Pharmacology and Experimental Therapeutics, 267, 250-258. 